\title{
High-wettability and Fire Resistant Separator Efficient Polysulfide Barrier for Increased Electrochemical Activity
}

\author{
Jiaofei Huo ${ }^{1, *}$, Yinwei Wang ${ }^{2}$ \\ ${ }^{1}$ Department of Mechanical and Electrical Technology, Xijing University, Xi' an 710123, China \\ ${ }^{2}$ Intelligent Manufacturing Research and Development Center, Xijing University, Xi' an 710123, \\ China \\ *E-mail: yinweiwangxj@yeah.net
}

doi: $10.20964 / 2019.10 .47$

Received: 31 May 2019 / Accepted: 26 June 2019 / Published: 30 August 2019

The common polypropylene separator could provide pathways for the transportation for the lithiumions. However, it fails to inhibit the polysulfide migration during the electrochemical reactions. As a result, the functional separators must be developed for inhibiting the shuttle effect of the soluble polysulfide. In our work, nano fibrous separator is prepared and used as the efficient barrier for the polysulfide migration. The PSA separator is fabricated by electrospinning method, using polysulfonamide membrane as the functional separator in the lithium-sulfur batteries. The electrochemical result shows that the initial specific capacity of the PSA separator is as high as 1506 $\mathrm{mAh} \mathrm{g}{ }^{-1}$ at the current density of $0.05 \mathrm{C}$. The PSA separator shows capacity of $1052 \mathrm{mAh} \mathrm{g}^{-1}$ after 100 cycles at the current density of $0.2 \mathrm{C}$.

Keywords: Polysulfonamide, Shuttle Effect, Fire Retardant, Separator, Li-S Battery, Electrochemical Performance

\section{$\underline{\text { FULL TEXT }}$}

(C) 2019 The Authors. Published by ESG (www.electrochemsci.org). This article is an open access article distributed under the terms and conditions of the Creative Commons Attribution license (http://creativecommons.org/licenses/by/4.0/). 